\title{
The Complex Relationship between Eosinophilic Esophagitis and Gastroesophageal Reflux Disease
}

\author{
David A. Katzka \\ Division of Gastroenterology and Hepatology, Mayo Clinic, Rochester, Minn., USA
}

\author{
Key Words \\ Eosinophilic esophagitis - Gastroesophageal reflux disease . \\ Dilated intercellular spaces
}

\begin{abstract}
That gastroesophageal reflux and eosinophilic esophagitis (EoE) may both lead to esophageal eosinophilia is well known. What is not known is how, if at all, these entities interact to contribute to this pathologic entity in specific patients and how often they occur in patients as synergistic contributors to the disease as opposed to distinct processes. There are several hypotheses by which gastroesophageal reflux disease (GERD) and EoE might interact to cause esophageal eosinophilia. These include (1) reflux of food from the stomach with increased antigenic exposure to esophageal epithelium; (2) reflux-induced dilation of intercellular spaces in the epithelium facilitating dendritic cell and antigen movement through the mucosa, and (3) a common inflammatory pathway activated by both GERD and EoE. Although these hypotheses appear plausible, supporting clinical data is not readily available. For example, it is unclear if the beneficial effect of proton pump inhibitors on esophageal eosinophilia is mediated through control of acid exposure to esophageal mucosa or independent antiinflammatory effects. There is also a lack of definitive evidence to support an increased incidence of GERD in the pe-
\end{abstract}

diatric population in the absence of evident risk factors such as obesity. One would think if GERD were an important cofactor in this disease, the incidence of GERD would rise similarly to EoE. It is speculated that GERD and EoE coexist and in some patients interact to facilitate esophageal eosinophilia and its sequelae. However, the presence and degree of this interaction likely varies remarkably. Their presence could be influenced by other factors such as age of the patient and genetic predisposition to EoE.

(C) 2014 S. Karger AG, Basel

\section{Introduction}

Gastroesophageal reflux disease (GERD) represents a pathophysiologic and diagnostic challenge in patients with esophageal eosinophilia and eosinophilic esophagitis (EoE). Basic questions still remain unanswered, such as how to differentiate esophageal eosinophilia associated with GERD from allergy-based disease and what role, if any, GERD plays in attenuating EoE. Extensive research has focused on the potential interactions from a disease understanding and treatment perspective. Nevertheless, from a practical point of view, the magnitude of these potential contributions of GERD are unclear as well. This review will focus on some of these questions.

\section{KARGER}

E-Mail karger@karger.com

www.karger.com/ddi
(C) 2014 S. Karger AG, Basel

0257-2753/14/0322-0093\$39.50/0
David A. Katzka, MD

Division of Gastroenterology and Hepatology, Mayo Clinic

200 First Ave., S.W

Rochester, MN 55905 (USA)

E-Mail katzka.david@mayo.edu 


\section{Potential Mechanisms by Which GERD May Contribute to EoE}

Although we typically associate gastroesophageal reflux with a disease (hence, 'GERD'), gastroesophageal reflux is a physiologic event. In a normal volunteer, the average time $\mathrm{pH}$ is less than 4 is $4.2 \%$ in the distal esophagus. Furthermore, depending on the laboratory, up to 73 events of all types of reflux (acid and nonacid) are still considered within the normal range. Notably, this impedance measurement only accounts for the number or episodes and not the duration (unlike $\mathrm{pH}$ measurements). As a result, reflux exposure times may be considerable in time, even when falling within a 'normal' range and nonacid reflux clearly occurs in patients with EoE [1].

It is also important and, perhaps obvious, to consider that the refluxate in gastroesophageal reflux may consist not only of secretions such as acid, bile and saliva, but also food. Furthermore, between the actions of teeth and antral grinding, food becomes a more homogenous mixture in suspension with facilitated exposure to the esophageal mucosa upon reflux as opposed to the initial bolus exposure upon swallowing. In addition to this potential repeat exposure of esophageal epithelium to food and its potential antigens, it is also important to note that clearance or refluxed food tends to be less efficient than deglutition, leading to longer esophageal antigen exposure. This results from less propulsive force with secondary peristalsis and the lack of swallowing and gravity to help clearance when reflux occurs in the recumbent position during sleep.

These physiologic considerations justify a potential contribution of gastroesophageal reflux to EoE. This may be particularly important in patients with pathologic reflux of acid and nonacid fluid if food antigens are present. Findings consistent with this mechanism are that even in consensus-proven cases [2] of EoE, esophageal eosinophilia is greater distally than proximally [3]. Although there is slower transit time through the distal esophagus in response to deglutition, this is likely a fraction of the time compared to reflux time on a daily basis. It is also important to note that even in the presence of proton pump inhibitor use and adequate suppression of gastric acid, the number of nonacid reflux episodes may or may not decrease but are by no means eliminated. There is also a theoretical concern that with inhibition of acid, food antigens may be better preserved, attenuating their ability to elicit an allergic reaction upon exposure to the esophageal epithelium.

\section{Dilation of Intercellular Spaces Facilitating Antigenic Exposure to Mediators of the Immune Pathway}

One of the general principals in gut allergy is the concept that dilation of intercellular spaces (DIS) in surface epithelial cells facilitates antigen penetration and exposure to antigen-recognizing cells. Emerging data suggests that this applies to EoE. DIS or what is termed pathologically as 'spongiosis' has been a hallmark of this disease [3]. Notably, patients in histologic remission also tend to have improvement of this finding.

A decade before the interest in EoE was ignited, dilation of esophageal epithelial intercellular spaces was described in gastroesophageal reflux by Dr. Roy Orlando and colleagues [4]. This lesion has been demonstrated consistently in GERD both from an experimental basis and on clinical evaluation. The mechanism by which reflux causes this dilation is unclear, but it is theorized that acid interferes with tight junction regulation. There is also recent data suggesting this histologic finding may be corrected with acid suppression [5].

One important question is how much acid exposure is required for this type of injury to occur. Is this a finding of severe acid exposure as one might encounter in patients with Barrett's esophagus or erosive esophagitis, making it less relevant to EoE? Studies suggest DIS may be the earliest pathologic finding in GERD, typically noted in patients with nonerosive GERD [4]. As a result, one might expect that this is a common lesion, and as additional data suggests, a marked increase in esophageal acid exposure is not required to sustain this type of injury. The commonality of this finding in patients with GERD and the theoretical import of such a mechanistic finding provide a logical two-hit hypothesis, i.e. reflux-induced DIS followed by augmented esophageal antigen exposure allows for another plausible means by which GERD may contribute to EoE.

\section{Augmentation of Similar Immunogenic and/or Inflammatory Pathways}

The immunogenic pathways of EoE are currently being elucidated. There is clear evidence of a Th2 type pathway strongly involving mast cells in addition to eosinophils. Candidate cytokines and messengers that have been strongly implicated include numerous interleukin molecules, chemokines such as eotaxin and RANTES, Toll-like receptors, and cytotoxic proteins [6]. On 
the other hand, the pathogenesis of GERD has always been thought to be a direct response of the esophageal epithelium to caustic exposure. This intuitively makes sense given the clear therapeutic response to acid-suppressing or -buffering medications, the association of stronger concentrations and longer exposures of hydrochloric acid to increasing degrees of gross esophageal injury, and the well-known effects of acid as a general caustic agent.

Recent data, however, has challenged this concept. For example, the effect of proton pump inhibitors may not be isolated to blocking acid secretion through the parietal cell $\mathrm{H}+, \mathrm{K}+\mathrm{ATPase}$. In fact, proton pump inhibitors may have a variety of additional actions in vitro [7] (table 1). In EoE, these effects may be evident in the identification of patients with proton pump inhibitor-responsive esophageal eosinophilia [8]. These patients clinically do not have evidence of increased esophageal epithelial acid exposure, yet respond clinically and histologically to proton pump inhibitors. It is also important to note that GERD, independently, may be associated with esophageal eosinophilia, further suggesting an immunogenic response [9].

Exciting work from the laboratory of Drs. Souza and Spechler has further demonstrated that at least a significant portion of esophageal injury in GERD is cytokine related. This can be demonstrated by an animal model using an esophagoduodenostomy to promote reflux in which active secretion of IL-1B and IL-8 occurs in esophageal epithelial cells $[10,11]$. Furthermore, histologic inflammation associated with persistent IL-8 in tissue exists at least 7 weeks after injury. They have also demonstrated (relevant to patients with proton pump inhibitor-responsive esophageal eosinophilia) that proton pump inhibitors block cytokine secretion of IL-4 and -13 in cultured EoE cells, inferring that perhaps some of their action in GERD may be through cytokine inhibition as well [11]. This mechanism is further reinforced by preliminary data from Dr. Molina-Infante and colleagues [23] suggesting that remission in proton pump inhibitor-responsive esophageal eosinophilia correlates with downregulation of eotaxin-3 and Th 2 cytokines, similarly to EoE after steroids. Thus, these groups of data suggest that there may be overlap in the immune mechanisms of reflux and allergy-induced esophageal eosinophilia, and that both may contribute through common pathways. Finally, a number of other potential interactions of GERD and EoE have been proposed by Drs. Souza and Spechler and colleagues $[12,13]$ (table 2 ).

Interaction of EoE and GERD
Table 1. Proposed mechanisms underlying anti-inflammatory effects of proton pump inhibitors

Antioxidant effects

Direct scavenging of reactive oxygen species

Replenishment of protective sulfhydryl molecules in the gastric mucosa

Induction of heme oxygenase-1

Effects on inflammatory cells

Inhibition of oxidative burst in neutrophils

Impaired phagocytosis of microorganisms by neutrophils

Decreased expression of adhesion molecules by neutrophils and monocytes

Impaired neutrophil migration

Effects on endothelial cells

Decreased expression of adhesion molecules

Decreased production of proinflammatory cytokines

Effects on epithelial cells

Decreased production of proinflammatory cytokines

Effects on gut microflora

Growth inhibitory and killing effects on a number of bacteria and fungi (see [7])

Table 2. Other mechanisms in which GERD and GERD treatment may contribute to EoE

Eosinophil secretory products alter esophageal motility so as to favor gastroesophageal reflux

Eosinophil secretory products alter esophageal motility so as to delay the clearance of refluxed material

EoE causes structural esophageal changes (mural thickening, fibrosis) that might affect lower esophageal sphincter function and esophageal clearance

Eosinophil secretory products render the esophageal mucosa more susceptible to injury by refluxed gastric juice (see [12])

\section{Evidence that GERD Is Not a Major Aspect of EoE}

Although the theoretical evidence associating GERD and EoE is compelling, there are a plethora of studies demonstrating that the putative mechanisms contributing to EoE may occur independent of gastroesophageal reflux. For example, dilated intercellular spaces are a prominent feature of EoE, even in the absence of confirmed acid exposure or response to proton pump inhibitors [14]. There is also clear data demonstrating dilated intercellular spaces improve with steroids after lack of response to proton pump inhibitors [3, 15], and preliminary data demonstrating a loss of filaggrin (a tight junction protein) in esophageal epithelia from EoE patients, which is restored with steroid treatment [Buttar and 
Katzka, unpubl. data]. This latter observation makes teleologic sense in that one of the gene abnormalities found in EoE patients codes for filaggrin [16]. Further, the cytokine increases described in these diseases do not fully overlap at this point; therefore, the postulation of a generalized nonspecific reaction that may be activated by both acid and allergy is not well proven at this time. Finally, in patients who are treated for esophageal eosinophilia on the basis of $\mathrm{pH}$ monitoring results, there is reasonable prediction of response to either proton pump inhibitors or steroids depending on a positive or negative result, respectively [17].

\section{There Is Not Clear Epidemiologic Evidence that GERD Has Increased in Parallel with EoE}

That there is an epidemic rise in pathologic reflux in the Western world is strongly inferred from the marked increase in refluxogenic factors [18], such as central obesity and its potential consequences, Barrett's esophagus, and adenocarcinoma of the esophagus. Thus, the rise in EoE might not only be explained by a modern era predisposition to allergy-based disease, but also to GERD. On the other hand, the greatest increase in Barrett's esophagus and cancer has been in a group of patients who tend to be older and with increased central adiposity, two characteristics atypical for EoE [19]. Studies examining the prevalence of GERD symptoms over two different time periods have not shown a sharp rise in symptoms [20] and certainly not a rise that approaches the increased incidence of EoE. Epidemiologic studies examining the incidence of GERD in children are scarce and the available data has not demonstrated a clear rise in GERD [21]. Finally, the prevalence of GERD in children follows a pattern of a peak in early years, a decrease in preteen years and a repeat peak toward adulthood. This is not the pattern seen in EoE.

\section{GERD and EoE May Be Epiphenomena of the Same Central Process}

Even though both GERD and EoE have risen in incidence over the past two decades, one has to rule out that this rise is from a common source that independently causes a rise in these two diseases. An example of this might be the decrease in Helicobacter pylori infection in the Western world. With eradication of $H$. pylori infection, theoretically those patients with chronic atrophic gastritis may have restoration of normal acid secretion. In the presence of lower esophageal sphincter dysfunction, this may allow for a resurgence of gastroesophageal reflux. Data further supporting this hypothesis includes an increase of Barrett's esophagus and esophageal cancer inversely proportional to a positive $H$. pylori status and worsening GERD symptoms after $H$. pylori treatment. On the other hand, $H$. pylori infection promotes a balance in the Th1 (inhibitory) and 2 allergic pathways. With the loss of $H$. pylori infection, the Th2 pathway is less opposed, promoting greater allergic diseases such as EoE [22]. It is also important to note that in addition to EoE, the incidence of many other allergic diseases clearly not uniformly related to GERD has risen. These include atopic dermatitis, eczema and asthma.

\section{Conclusion}

There are excellent reasons to link GERD and EoE as two diseases contributing to a common disease. These reasons are sound from a theoretical point of view and there is extensive laboratory and patient evidence to support this association. On the other hand, the epidemiology has not borne out a similar rise in either disease and the target populations are different. Furthermore, EoE (for many reasons independent of GERD) has appeared in the past two decades without GERD being established as a confounding mechanism. Another possibility is that although GERD has not increased to the same degree as EoE, it is still common and may act as a facilitator of EoE. It is likely, however, that there are patients with EoE in which GERD is an important pathologic contributor. It is also likely that the presence and contribution of GERD varies with the age of the patient and the number of independent factors that predispose to EoE. The magnitude of these numbers has yet to be determined.

\section{Disclosure Statement}

The author declares that no financial or other conflict of interest exists in relation to the content of the article.
Katzka 


\section{References}

1 Rosen R, Furuta G, Fritz J, Donovan K, Nurko $\mathrm{S}$ : Role of acid and nonacid reflux in children with eosinophilic esophagitis compared with patients with gastroesophageal reflux and control patients. J Pediatr Gastroenterol Nutr 2008;46:520-523.

-2 Liacouras CA, Furuta GT, Hirano I, Atkins D, Attwood SE, Bonis PA, Burks AW, Chehade M, Collins MH, Dellon ES, Dohil R, Falk GW, Gonsalves N, Gupta SK, Katzka DA, Lucendo AJ, Markowitz JE, Noel RJ, Odze RD, Putnam PE, Richter JE, Romero Y, Ruchelli E, Sampson HA, Schoepfer A, Shaheen NJ, Sicherer SH, Spechler S, Spergel JM, Straumann A, Wershil BK, Rothenberg ME, Aceves SS: Eosinophilic esophagitis: updated consensus recommendations for children and adults. J Allergy Clin Immunol 2011;128:3-20.e6.

$\checkmark 3$ Mueller S, Neureiter D, Aigner T, Stolte M: Comparison of histological parameters for the diagnosis of eosinophilic oesophagitis versus gastro-oesophageal reflux disease on oesophageal biopsy material. Histopathology 2008;53:676-684.

4 Tobey NA, Carson JL, Alkiek RA, Orlando RC: Dilated intercellular spaces: a morphological feature of acid reflux - damaged human esophageal epithelium. Gastroenterology 1996;111:1200-1205.

$\checkmark 5$ Calabrese C, Bortolotti M, Fabbri A, Areni A, Cenacchi G, Scialpi C, Miglioli M, Di Febo G: Reversibility of GERD ultrastructural alterations and relief of symptoms after omeprazole treatment. Am J Gastroenterol 2005;100:537542.

6 Rothenberg ME: Biology and treatment of eosinophilic esophagitis. Gastroenterology 2009; 137:1238-1249.

7 Kedika RR, Souza RF, Spechler SJ: Potential anti-inflammatory effects of proton pump inhibitors: a review and discussion of the clinical implications. Dig Dis Sci 2009;54:23122317.
-8 Molina-Infante J, Ferrando-Lamana L, Ripoll C, Hernandez-Alonso M, Mateos JM, Fernandez-Bermejo M, Duenas C, FernandezGonzalez N, Quintana EM, Gonzalez-Nunez MA: Esophageal eosinophilic infiltration responds to proton pump inhibition in most adults. Clin Gastroenterol Hepatol 2011;9: 110-117.

-9 Ngo P, Furuta GT, Antonioli DA, Fox VL: Eosinophils in the esophagus - peptic or allergic eosinophilic esophagitis? Case series of three patients with esophageal eosinophilia. Am J Gastroenterol 2006;101:1666-1670.

10 Souza RF, Huo X, Mittal V, Schuler CM, Carmack SW, Zhang HY, Zhang X, Yu C, HormiCarver K, Genta RM, Spechler SJ: Gastroesophageal reflux might cause esophagitis through a cytokine-mediated mechanism rather than caustic acid injury. Gastroenterology 2009;137:1776-1784.

11 Cheng E, Zhang X, Huo X, Yu C, Zhang Q, Wang DH, Spechler SJ, Souza RF: Differences in eotaxin-3 expression after stimulation with IL-13 and IL-4 in esophageal squamous cell lines from patients with eosinophilic esophagitis and GERD. Gastroenterology 2011; 140(suppl 1):S187, Abstract 1117.

12 Spechler SJ, Genta RM, Souza RF: Thoughts on the complex relationship between gastroesophageal reflux disease and eosinophilic esophagitis. Am J Gastroenterol 2007;102: 1301-1306.

13 Merwat SN, Spechler SJ: Might the use of acid-suppressive medications predispose to the development of eosinophilic esophagitis? Am J Gastroenterol 2009;104:1897-1902.

14 Odze RD: Pathology of eosinophilic esophagitis: what the clinician needs to know. Am J Gastroenterol 2009;104:485-490.

15 Mueller S, Aigner T, Neureiter D, Stolte M: Eosinophil infiltration and degranulation in oesophageal mucosa from adult patients with eosinophilic oesophagitis: a retrospective and comparative study on pathological biopsy. J Clin Pathol 2006;59:1175-1180.

-16 Blanchard C, Wang N, Stringer KF, Mishra A, Fulkerson PC, Abonia JP, Jameson SC, Kirby C, Konikoff MR, Collins MH, Cohen MB, Akers R, Hogan SP, Assa'ad AH, Putnam PE, Aronow BJ, Rothenberg ME: Eotaxin-3 and a uniquely conserved gene-expression profile in eosinophilic esophagitis. J Clin Invest 2006; 116:536-547.
17 Francis DL, Foxx-Orenstein A, Arora AS, Smyrk TC, Jensen K, Nord SL, Alexander JA, Romero Y, Katzka DA: Results of ambulatory $\mathrm{pH}$ monitoring do not reliably predict response to therapy in patients with eosinophilic oesophagitis. Aliment Pharmacol Ther 2012;35:300-307.

18 Corley DA, Kubo A, Levin TR, Block G, Habel L, Rumore G, Quesenberry C, Buffler P: Race, ethnicity, sex and temporal differences in Barrett's oesophagus diagnosis: a large community-based study, 1994-2006. Gut 2009;58: 182-188.

19 Leggett CL, Nelsen EM, Tian J, Schleck CB, Zinsmeister AR, Dunagan KT, Locke GR 3rd, Wang KK, Talley NJ, Iyer PG: Metabolic syndrome as a risk factor for Barrett esophagus: a population-based case-control study. Mayo Clinic Proc 2013;88:157-165.

$>20$ Ness-Jensen E, Lindam A, Lagergren J, Hveem K: Changes in prevalence, incidence and spontaneous loss of gastro-oesophageal reflux symptoms: a prospective populationbased cohort study, the HUNT study. Gut 2012;61:1390-1397.

21 Ruigomez A, Johansson S, Wernersson B, Fernandez Cantero O, Garcia Rodriguez LA: Gastroesophageal reflux disease in primary care: using changes in proton pump inhibitor therapy as an indicator of partial response. Scand J Gastroenterol 2012;47:751-761.

22 Dellon ES, Peery AF, Shaheen NJ, Morgan DR, Hurrell JM, Lash RH, Genta RM: Inverse association of esophageal eosinophilia with Helicobacter pylori based on analysis of a US pathology database. Gastroenterology 2011; 141:1586-1592.

23 Molina-Infante J, Rivas MD, Vinagre-Rodriguez $\mathrm{G}$, et al: Remission in proton pump inhibitors-responsive esophageal eosinophilia correlates with downregulation of eotaxin-3 and TH2 cytokines, similarly to eosinophilic esophagitis after steroids. Gastroenterology 2013;144(suppl 1):S484. 